\title{
The Influence of Modern Information Technologies on the Efficiency of High-Tech Companies' Performance
}

\author{
Kazmina I.V.* \\ Military Educational Scientific Center \\ Air force Academy named after professor N. E. Zhukovsky \\ and Y. A. Gagarina \\ Voronezh, Russia \\ e-mail: kazminakazmina@yandex.ru \\ Muratova O.I \\ Voronezh State Technical University \\ Voronezh, Russia \\ e-mail: muratova_o_i@mail.ru
}

\author{
Schegoleva T.V. \\ Voronezh State Technical University \\ Voronezh, Russia \\ e-mail: bosyanyka@mail.ru \\ Volodina N.L. \\ Voronezh state technical University \\ Voronezh, Russia \\ e-mail: volonataly.79@mail.ru
}

\author{
Slinchuk S.A. \\ Voronezh State Technical University \\ Voronezh, Russia \\ e-mail: sslinchuk@gmail.com
}

\begin{abstract}
The subject of the study is the organizational and economic relations arising in the process of introducing current information technologies. The purpose of this article is to justify the need for the introduction of modern information technologies in the work of a high-tech company and to determine the optimality criterion for the information technologies in the manufacturing of high-tech products. As a result of the study, it was found that modern information technologies have significant potential for accelerating innovative processes, therefore, the investment indicators in the development of the digital potential of a company are an important factor in its competitiveness in the current conditions. Besides, the introduction of modern information technologies at high-tech companies also leads to other positive effects in the economic and social spheres. Using the research results, the optimality criteria for the information technologies in the manufacturing of high-tech products are substantiated, which are based on the economic assessment of the results of the influence of information technologies on the final result of their use, the impact of information technologies on technological operations of data processing and transfer in computing systems, as well as the impact of information technology on the technological processes of creating new product samples.
\end{abstract}

Keywords - high-tech products, information, information technology, automation system, life cycle, optimality criterion, computing systems.

\section{INTRODUCTION}

At the end of the last century, mankind has stepped into a new stage of its development, which is called a post-industrial society. This is a society in which physical labor gives way to the leading position of intellectual activity. The key production resources are knowledge, information, and scientific achievements $[1,2,8]$. Human capital and innovation, combined with information technology - these are the main driving forces of the new economy. These are information technologies and systems, along with advanced technologies of material production, that can significantly increase labor productivity and the quality of products with a significant reduction in the timing of manufacturing of products which meet the needs and expectations of consumers. Information technology is a combination of methods, software tools and hardware, combined into a technological chain that provides for the data collection, processing, storage, display, distribution, transmission, use and the protection of information using computer-engineering means (CEM). The main goal of information technology is to obtain the information of new quality, by processing primary data, on the basis of which management decisions are developed.

The initial experience in the development and implementation of information technology, obtained in the 1980s, made it possible to realize the need to integrate systems that implement various information technologies into a single complex, which was called IACS - an integrated automated control system. The emergence and implementation of IACS are clearly associated with highly automated production complexes such as flexible automated production. Further development showed the feasibility of introducing IACS in high-tech companies with low level of technological process automation. At the beginning of the $21^{\text {st }}$ century, the creation of an integrated information environment (IIE) within the company covering all stages of the life cycle (LC) of products manufactured by this company was significant achievement $[3,4,6]$.

It was the idea of IIE and informational integration of the life cycle stages that became the basis for the development of the approach that received the name of Continuous Acquisition 
and Lifecycle Support in the USA - continuous information support for supplies and life cycle. Here the key principle of CALS is implemented: the information that once appeared at any stage of the LC is stored in the IIE and becomes available to all participants in this and other stages [1]. This helps avoiding duplication, transcoding, and unauthorized changes to data, eliminating errors associated with these procedures and reducing labor, time, and financial resource consumption.

Today, the idea of CALS was formed into a whole direction in the field of information technology and took shape in the form of a series of international standards ISO (International Standards Organization). In recent years, CALS methods and ideas and the information technologies based on them (CALS technologies) have been used in Russia, primarily in defense industry companies that supply high-tech products to the foreign market.

\section{Methodology}

It should be noted that the situation with domestic electronic business remains rather complicated. This is due to the poor business activity of the Russian population. However, there is confidence among the experts that this technology will replace the already existing types of commerce. Currently, if a company does not have a website on the Internet, it simply does not exist in business. A corporate website can become a powerful means of activating sales and, therefore, ensure that the company achieves maximum profit. In this regard, the influence and impact of modern information technologies, including technologies used on the Internet, on the development of the economy are very strong.

Due to the widespread use of computer technology, wireless technologies, and technological process robots at hightech companies, we can talk about the use of wireless telecommunication systems, large functioning databases and remote ("cloud") storages in the company management system, about development and implementation of new software and other digital technology tools. Given these changes, it has become easier to keep accounts, calculate the production model, while saving a significant amount of time and material resources for the introduction of new technological processes.

Nowadays, computer and software knowledge is required of not only entrepreneurs and managers, but also of all modern people involved in the production, sale, and purchase of products and services. Knowledge of such programs as text editors, graphic editors, spreadsheets, databases, and others, including applications related to the organization of production process management and electronic business is of the utmost importance. The scope of e-business is significant and includes management organization, electronic commerce, banking operations, reengineering of business processes, insurance operations, operations on the stock exchange, etc.

There is significant potential for using modern information technologies in the companies' activities. These technologies have significant potential for accelerating, for example, innovative processes; therefore investment indicators in the development of the digital potential of a company are an important factor in its competitiveness in modern conditions. Besides, the introduction of modern information technology at a com- pany also leads to the emergence of other positive effects in the economic and social spheres.

Figure 1 shows the manifestations of the positive effect in the economic and social spheres generated by the introduction of modern information technologies.

It follows from the analysis of the influence of modern information technologies on the development of economic relations that the main purpose of using modern information technologies is to assist management, respond promptly to market dynamics, create, maintain, and deepen competitive advantage, implement reengineering and monitoring of the production processes, improve the security of the company's information resources. At the same time, information technology is the most important constructive factor in the economic success of a high-tech company.

Based on the analysis of the impact of modern information technologies on improving the economic relations between enterprises and organizations, the following conclusions can be drawn. As a result of the use of modern information technologies, new characteristic features of economic relations between enterprises and organizations have become the manifestations that reflect specific features by means of using:

- integrated procedures and tools based on digital equipment;

- economic and mathematical models, methods, and software tools;

- network communications and electronic document flow;

- virtual offices, in order to increase the independence of employees of the company and the effectiveness of contact with potential buyers of products;

- distributed databases and computing networks based on wireless cloud technologies.

\section{RESULTS AND DISCUSSION}

To understand the essence of the issues of optimizing information technology used in a high-tech company in manufacturing of products, it must be borne in mind that in economics an optimal solution is understood to be, as a rule, the most reasonable solution providing the greatest profit for the company. To apply the mathematical methods of optimizing information technology, it is necessary to formulate optimization criteria, which can be expressed numerically and form the basis of all analytical and numerical solutions. The matter of choosing an optimization criterion is one of the most important in optimization processes, at the same time it is among of the most difficult ones.

Generally, the criterion for optimizing information technology is the economic indicator of production profitability. However, in some cases, labor productivity, time expenditures for the production of a unit of output, labor expenditures or other parameters can be taken as the optimization criterion. At the optimal value of the parameter, the optimization criterion assumes the minimum (or maximum) value. Therefore, the optimization problem is reduced to finding the extremum of the objective function $[11,13]$. 
Economic benefits



Fig. 1. Manifestations of the positive effect in the economic and social spheres generated by the introduction of modern information technologies

The statement of the problem of optimizing the information technologies used by an industrial enterprise in the manufacturing of high-tech products suggests the following conditions:

(i) the availability of the optimization object - information technology used by IACS of the manufacturing enterprise, and the optimization goal. The wording of each optimization problem should require the extremum of one value at the working values of the input, output, and control parameters processed by the IACS;

(ii) the availability of optimization resources, which means the ability to select the values of some parameters of the optimized production;

(iii) the existence of material, financial, and time constraints in the manufacturing of high-tech products;

(iv) the possibility to quantify the optimized value, which allows one to compare the economic effects of the choice of certain control actions of IASU.

The classical foundations of optimization are determined by previously developed methods for the study of functions in mathematical analysis. Not just any function $(x)$ should be calculated in the process of optimization, transferring the target function (functionality $F$ ) to the minimum (maximum), but only the one that fits the limitation system. A numerical indi- cator of the functional $F$ is used as an optimization criterion, which expresses the marginal measure of the economic effect of a decision made using information technologies. The calculated numerical indicators are used for a comparative assessment of possible solutions (alternatives) and the choice of the best one. Therefore, the following requirements must be imposed on the optimization criterion:

(i) reflect the impact of the assessment of the most significant aspects of the information management process;

(ii) make clear economic sense;

(iii) be calculated using computer technology;

(iv) be numerical.

The most common optimization problems are finding the minimum (or maximum) of the functional $F$. In this case one calculates value $\mathrm{n}$ of the variables $x_{1}, x_{2}, \ldots, x_{n}$, when function $F\left(x_{1}, x_{2}, \ldots, x_{n}\right)$ takes on the extreme value $F=\min (\max )$. Figure 2 presents graphic display of the target function $f(x)$ with its minimum at $x_{0}$.

It can be noted that the functional $F$ at the point $x_{0}$ has a local minimum that corresponds to such an informational process, in which the best solution to the managerial problem is realized in manufacturing high-tech products in accordance with some predetermined criterion. 


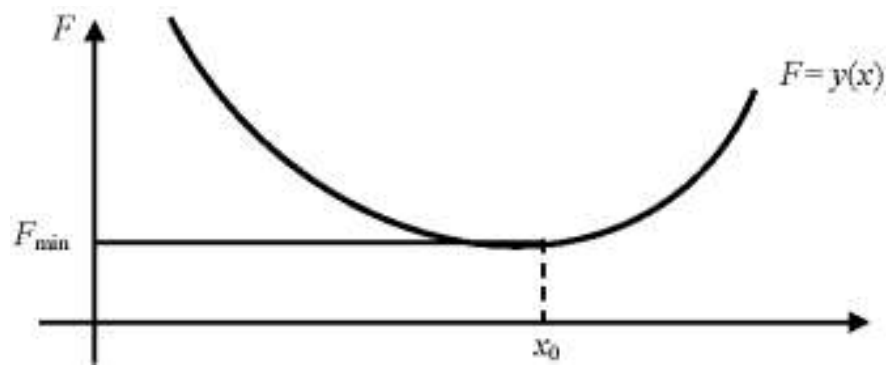

Fig. 2. Graphic display of the target function $f(x)$

When setting the specific optimization problems, optimization criteria should be written in the form of an analytical expression. In this case, the optimization criterion can be represented as a function of input, output, and control parameters, which are also formed using information technologies:

$$
F_{\text {min }}=F\left(X_{1}, X_{2}, \ldots, X_{\mathrm{n}}, Y_{1}, Y_{2}, \ldots, Y_{n}, W_{1}, W_{2}, \ldots, W_{n}\right),
$$

where $F$-optimization criterion; $X$ - controlled input parameters; $Y$ - output parameters; $W$ - controlled regulating parameters.

The presence of a mathematical model (provided that it reliably describes the technological and managerial processes at the company) allows one to solve, by analytical or numerical methods, the task of optimizing the information technologies used at the industrial enterprise in the manufacturing of hightech products.

Thus, initially, the optimization problem is reduced to finding the extremum (minimum or maximum) of the target function, then the optimal management solution is determined from the possible solutions (alternatives) by means of the following expression:

$$
F_{\text {opt }}=\min \left\{F_{\min 1}, F_{\min 2}, \ldots, F_{\min \mathrm{N}}\right\},
$$

where $F_{\min 1}, F_{\min 2}, \ldots, F_{\min N}$ - numerical values of the functional $F$, which expresses the marginal measure of the economic effect of the decision made using information technologies; $N$ - number of possible solutions (alternatives) concerning the managerial impact of information technologies on manufacturing the products.

When optimizing the information technologies used at a high-tech company in the manufacturing of products, the following basic requirements should be put forward for processing information flows $[5,9,11]$ :

(i) guaranteed delivery of information to the relevant executors at the specified time and place in order to timely solve the problems of managing production and economic systems;

(ii) reliability and accuracy of information as the basis for correctness of decisions;

(iii) security of information flows in accordance with applicable law with the use of hardware, software, and firmware means.

It should be noted that in order to optimize and quantify the effectiveness of possible options for designed or existing information technologies, functional and resource criteria, as well as criteria for saving social time, can be used. In addition, partial criteria for evaluating the effectiveness of information technology can be used.

A feature of the functional criterion is that in this case, the degree of achievement with a given information technology of the desired characteristics of the information process that the user needs is optimized. For instance, such characteristics include:

(i) data transfer rate, amount of memory for storing information;

(ii) quality of generated graphic information;

(iii) probability of the correct transfer or transformation of information;

(iv) level of noise immunity of transmitted information.

A feature of the resource criterion is that the quantity and quality of resources required for the implementation of this information technology are optimized. These resources may include:

(i) software for information processes and process equipment necessary for the successful implementation of industrial production;

(ii) the number and level of training of IT personnel required for the implementation of information technology;

(iii) energy expenditures for the implementation of the information process or this technology;

(iv) the length of time required to implement the information process with a given technology of its organization.

Resource efficiency criteria allow one to fundamentally compare different types of information technologies. Besides, they provide an opportunity to quantify the effect obtained as a result of using these technologies in terms of their social usefulness in terms of saving various types of society's resources.

The criterion of saving social time (proposed by Russian scientists in the field of information technology) is one of the most general measures for the development of the society; it seems suitable for comparative quantitative assessment of the effectiveness of various types of information technologies. This is the most general indicator of technology of any kind (production, social, or information).With the help of this criterion, the most useful information technologies for the society from the social point of view are identified, which save the greatest amount of social time, freeing it for other purposes, including for the development of the society.

Partial criteria for evaluating the effectiveness of information technology options may include the following $[7,14,15]$.

Information processing timeliness indicator $K_{\mathrm{ipt}}$. In this case, the criterion for assessing the timeliness of processing information of input, output, and control parameters generated using various options of information technology can be determined by the expression:

$$
K_{i p t}=T_{m p}-T_{p} / T_{p},
$$


where $T_{m p}$ - the required time for information processing (corresponding planned reporting interval); $T_{p}$ - actual time for information processing.

The calculated ratio obtained for determining the timeliness of information processing is applied in the range of values of $K_{i p t}>0$.

Indicator of the quality and completeness of information technology. Functional completeness $K_{f c}$ is used as such criterion; the ratio of the areas of automated information processing to the area of information processing for the functioning of the entire control system:

$$
K_{f c}=\frac{Q a}{Q y},
$$

where $Q a$ - area of automated information processing of the company; $Q y$ - areas of information processing for the functioning of the entire control system of the company.

This indicator determines the degree of use of information technology at an industrial enterprise in the manufacturing of high-tech products.

Indicator of satisfaction of information needs of the user. This criterion is most often used in the analysis of various options for information processing technologies. In this case, the criterion for evaluating options for data processing technologies can be determined by:

$$
K_{s a t}=\frac{C y}{C p},
$$

where $C_{y}-$ cost estimate of satisfaction of information needs of the user; $C_{p}$ - expenditures associated with development, purchase, introduction, modification, and operation of data processing technology.

When evaluating the effectiveness of options for data processing information technologies, preference is given to a variant with greater value of $K_{\text {sat }}$. The qualitative assessment of information technologies is based on a variety of methods and procedures for their application.

Due to the presence of a large number of economic characteristics (parameters) that allow evaluation of the efficiency (economic effect) of high-tech production, other private indicators of the effectiveness of information technology options can be used. At the same time, the actual economic effect at a high-tech company should be determined on the basis of accounting and cost-benefit comparisons for specific applications of information technology.

\section{CONCLUSION}

Thus, the optimality criteria for the information technology in the manufacturing of high-tech products are determined based on the economic assessment of the results of the influence of information technologies on the final result of their use, the impact of information technologies on technological processes of data processing and transmission in computer systems, and the impact of information technologies on technological processes of creating new product samples.

\section{References}

[1] J.L. Gissel, "A case of fixed asset accounting: Initial and subsequent measurement", J. of Account. Ed., vol. 37, pp. 61-66. Retrieved from: https://doi.org/10.1016/j.jaccedu.2016.10.001

[2] A. Neligan, "Digitalisation as Enabler Towards a Sustainable Circular Economy in Germany", Intereconomics, vol. 53, iss. 2, pp 101-106, March 2018, Retrieved from: https://doi.org/ 10.1007/s10272-018-0729-4.

[3] M.A. Gurina, J.V. Rumyanceva, "Comprehensive tools and methodologies quality improvement in the management competitiveness trade enterprises", Proc. of Voronezh State Univer. of Engineer. Technol., vol. 81, no. 2, pp. 320-335, 2019, Retrieved from: https://doi.org/10.20914/2310-1202-2019-2-320-335

[4] V. KalimullinL, D.K. Levchenko, Y.B. Smirnova, E.S. Tuzikova, "Foreign experience of supporting development of technologies of storage ofenergy", Proc. of Voronezh State Univer. of Engineer. Technol., vol. 81, no. 2, pp. 341-351, 2019, Retrieved from: https://doi.org/ 10.20914/2310-1202-2019-2-341-351

[5] Y.A. Salikov, V.S. Mikhailiuk, "Methodological approach to the terminological analysis of the key concepts of economic security", Proc. of the Voronezh State Univer. of Engineer. Technol., vol. 81, no. 2, pp. 387-392, 2019, Retrieved from: https://doi.org/10.20914/2310-12022019-2-387-392

[6] N.S. Serebryakova, A.V. Petrikov, "The principles of design and the organization of functioning of innovative infrastructures in the conditions of the Industry 4.0", Proc. of Voronezh State Univer. of Engi. Technol., vol. 80, no. 4, pp. 384-387, 2018, Retrieved from: https://doi.org/10.20914/2310-1202-2018-4-384-387

[7] D.A. Shageev, T.A. Chuhonceva, "Universal rapid method of assessment and management decision-making of situational problems in the enterprise", Proc. of Voronezh State Univer. of Engineer. Technol., vol. 81, no. 2, pp. 359-376, 2019, Retrieved from: https://doi.org/10.20914/2310-1202-2019-2-359-376

[8] V.V. Kukartsev, A.A. Boyko, O.A. Antamoshkin, "The simulation model of fixed assets reproduction of mechanical engineering enterprises" [Int. Russ. Automation Conf., RusAutoCon], 2018, DOI 10.1109/RUSAUTOCON.2018.8501776.

[9] O.O. Lukina, V.V. Dudchak, "Generalized indicator and classification structures of the capital of the industrial enterprises", Proc. of Voronezh State Univer. of Engineer. Technol., vol. 80, no. 3, pp. 423-428, 2018, Retrieved from: https://doi.org/10.20914/2310-1202-2018-3-423-428

[10] G.I. Konovalova, "The methodology of the universal system of timely control of diverse dynamic production", Manag. in Russ. and abroad, no. 5, pp. 89-95, 2016.

[11] G.I. Konovalova, "The methodology of timely stock management in the dynamic diverse machinebuilding production", Manag. in Russ. and abroad, no. 6, pp. 137-143, 2017.

[12] "Industry 4.0": Digital enterprise creation. Global analysis of concepts "Industry 4.0", 2016 / PwC, 2017.

[13] The Fourth Industrial Revolution, by Klaus Schwab, World Economic Forum, 2016. Retrieved from: https://www.weforum.org/ about/thefourthindustrial-revolution-by-klaus-schwab (access date: 01.03.2019).

[14] N.M. Rozanova, A.V. Yushin, "The mechanism of transformation of the network market in the digital age", Terra Econ., vol. 13, no. 1, pp. 73-88, 2015

[15] S. Ruutu, T. Casey, V. Kotovirta, "Development and competition of digital service platforms: a system dynamics approach", Technol Forecast. and Soc. Change, 2017.

[16] N.M. Rozanova, I.V., "The digital model for contemporary business", The J. of Econ. Theory, vol. 16, no. 1, pp. 46-59, 2019 